\title{
A case of Lassa fever: experience at St Thomas's Hospital
}

\author{
C B COOPER, W R GRANSDEN, MARGARET WEBSTER, MARY KING, MARY O'MAHONY, \\ SUSAN YOUNG, J E BANATVALA
}

\begin{abstract}
An 18-year-old Nigerian girl, normally resident in Jos, was admitted to hospital for five days before she was diagnosed as having Lassa fever. There were several atypical features in the early stages of her illness, notably the absence of prostration, pharyngitis, or bradycardia and the development of appreciable leucocytosis. Consequent control and surveillance measures required checks for 21 days on 173 people who had had contact with her inside and outside the hospital. Contacts were categorised as first line if they had handled her or specimens without taking precautions to avoid direct skin contact with her excretions, secretions, and blood; other contacts were categorised as second line. During her time in hospital she was managed in a single room on a general ward. She visited a number of investigative departments within the hospital, and her specimens were examined in five clinical laboratories. Despite this no secondary cases occurred among either first- or second-line contacts, and there was no serological evidence of subclinical infection among any of the contacts tested (159 people).
\end{abstract}

\section{Introduction}

Lassa fever has acquired a mythology out of all proportion to its clinical importance in Britain. The diagnosis may be far from easy to make even when the possibility is considered. The consequences of having a patient with undiagnosed Lassa fever on a general medical ward of a central London hospital are far reaching and time consuming for all concerned.

\section{Case history}

An 18-year-old Nigerian girl lived in central Jos, a university town of more than 100000 inhabitants, but made daily journeys by bus to the outskirts of the city, where she taught in a school. On 17 December 1981 she developed a fever and was given chloroquine for one day only. No diagnostic procedure was undertaken, and the fever rapidly subsided. On 23 December she went by car to Kano and then by air to London. Eight days after her arrival in Britain she became febrile and complained of abdominal colic associated with bilious vomiting and retro-orbital pain. She had neither sore throat nor other respiratory symptoms. There was frequency of micturition but no dysuria. A general practitioner examined her on 4 January 1982 and referred her to St Thomas's Hospital, to which she was taken by minicab.

In spite of fever of $38^{\circ} \mathrm{C}$, on examination she appeared to be relatively well without dehydration or hypotension. The pulse was regular at 96 beats $/ \mathrm{min}$. There was no evidence of pharyngeal inflammation or mucocutaneous haemorrhage. The abdomen was slightly tender. Haematological tests showed a haemoglobin concentration of $13.8 \mathrm{~g} / \mathrm{dl}$,

St Thomas's Hospital, London SE1 7EH

C B COOPER, BSC, MRCP, medical registrar

W R GRANSDEN, MA, MB, lecturer in microbiology

MARGARET WEBSTER, SRN, nursing officer, infection control

MARY KING, MSC, MD, senior registrar in virology

MARY O'MAHONY, MSC, MRCPI, senior registrar in community medicine

J E BANATVALA, MD, FRCPATH, professor of clinical virology

Communicable Disease Surveillance Centre, PHLS, London NW9 5EQ

SUSAN YOUNG, MRCP, DCH, deputy director white blood cell count $5.9 \times 10^{9} / 1$ (neutrophils $52 \%$, lymphocytes $29 \%$ ), and erythrocyte sedimentation rate $19 \mathrm{~mm}$ in the first hour. Results of a Paul-Bunnell test were negative. No malarial parasites were seen on thick and thin blood films. There was proteinuria, but microscopy of the urine yielded normal results.

Despite careful questioning she did not admit to having visited a rural area or a hospital, and the clinical picture without pharyngitis, prostration, or bradycardia did not conform with that of Lassa fever. She was therefore admitted to a single room in a general ward for further investigation, but "secretion, excretion, and blood" isolation precautions were observed.

For two days after admission there was little clinical change. The pulse quickened to 114 beats/min and a third heart sound was heard. An electrocardiogram showed repolarisation changes compatible with myocarditis. Thick and thin blood films were examined daily and no malarial parasites seen. Serial blood cultures remained sterile. The cerebrospinal fluid was normal. From the fourth day she vomited more frequently and required intravenous fluids. Blood concentrations of urea and creatinine began to rise (urea $18.3 \mu \mathrm{mol} / \mathrm{l}(110 \mu \mathrm{g} / 100 \mathrm{ml})$, creatinine $201 \mu \mathrm{mol} / \mathrm{l}(2.3 \mathrm{mg} / 100 \mathrm{ml})$ ), and enzyme activities rose progressively (creatinine kinase $123 \mathrm{U} / 1$ (normal $<65 \mathrm{U} / \mathrm{l}$ ), hydroxybutyrate dehydrogenase $4015 \mathrm{U} / 1$ (normal $<140 \mathrm{U} / 1$ ), asparate transaminase $4440 \mathrm{U} / 1$ (normal $<18 \mathrm{U} / \mathrm{l}$ ), and alanine transaminase $850 \mathrm{U} / 1$ (normal $<20 \mathrm{U} / \mathrm{l})$ ). An isotope liver scan excluded an abscess but showed diffusely abnormal uptake consistent with severe hepatitis. By the fifth day she had developed facial oedema extending to the neck. Haematological tests now showed a white blood cell count of $22.9 \times$ $10^{6} / 1$ (neutrophils $65 \%$, atypical monocytes $11 \%$, metamyelocytes $2 \%$ ). Platelets were $94 \times 10^{\circ} / 1$ and the coagulation times prolonged (prothrombin ratio $2 \cdot 1$, partial thromboplastin time $62 \cdot 3 \mathrm{~s}$ ), though levels of fibrinogen and fibrin degradation products remained normal.

Exclusion of more likely diseases such as malaria, typhoid fever, hepatitis A and B, infectious mononucleosis, liver abscess, and septicaemia coupled with the fact that the patient's husband, who lived in Britain, stated that his wife had visited relatives in a rural area $10 \mathrm{~km}$ from Jos led us to consider Lassa fever as the probable diagnosis. Furthermore, impaired coagulation meant a risk of uncontrollable haemorrhage. She was therefore transferred to Coppetts Wood Hospital on 8 January. Heavy snow precluded transport of specimens to the PHLS Centre for Applied Microbiology and Research, Porton Down, until 11 January, and on 12 January Lassa fever virus was identified. ${ }^{1}$ Details of the patient's progress in strict isolation are described separately. ${ }^{1}$

\section{Surveillance and control measures}

As soon as the patient had been transferred with a probable diagnosis of Lassa fever, St Thomas's Hospital set in motion measures to control spread of the disease and instituted a surveillance programme. The district community physician arranged for her cubicle to be fumigated, and an emergency committee was convened and met daily throughout the period of surveillance. The Communicable Disease Surveillance Centre was informed.

The number of contacts was disturbingly large. Outside the hospital they included the patient's husband and other household contacts, the general practitioner who had examined her, the minicab driver who had brought her to hospital, and the ambulance staff who had conveyed her to Coppetts Wood Hospital. Within the hospital the contacts included medical and nursing staff, a medical student, domestic staff, plumbers, porters, laboratory staff, and service engineers. While in hospital the patient had visited several investigative departments including those of nuclear medicine, $x$-ray, and ultrasonography. Specimens had been examined in the departments of haematology, chemical pathology, microbiology, virology, and immunology.

Contacts were categorised as first line if they had handled the patient or her specimens without taking precautions to avoid direct skin contact with her excretions, secretions, or blood. Other contacts were categorised as second line. All those under surveillance were asked 
to record their body temperature daily for 21 days from the date of last contact with the patient or her specimens. First-line contacts who developed fever were to be transported by special ambulance to Coppetts Wood Hospital; second-line contacts who developed fever were to be observed for 24 hours in specially designated cubicles at $\mathrm{St}$ Thomas's Hospital staffed by trained volunteer nurses and to be transported to Coppetts Wood Hospital by special ambulance if their fever persisted. As febrile episodes are particularly common in January, however, we decided to regard only temperatures of $\geqslant 38^{\circ} \mathrm{C}$ as important in both first- and second-line contacts.

The 124 first-line contacts included the patient's husband and general practitioner and 86 laboratory workers. The 49 second-line contacts included 37 within the hospital (table). Two of these, both

Details of contacts under surveillance

\begin{tabular}{lccc}
\hline & In hospital & In community & Total \\
\hline No of first-line contacts* & 122 & $2{ }^{\dagger}$ & 124 \\
No of second-line contacts & 237 & 12 & 2 \\
No developing temperature, $\geqslant 38^{\circ} \mathrm{C}_{+}^{+}$ & 2 & & 1 \\
No admitted to St Thomas's Hospital & 1 & 14 & 173 \\
\hline Total & 159 & 14 & \\
\hline
\end{tabular}

* No first-line contacts developed a temperature $\geqslant 38^{\circ} \mathrm{C}$ or were admitted to Coppetts Wood Hospital.

+ Patient's husband and general practitioner.

$\ddagger$ Five first-line and five second-line contacts developed a temperature $<38^{\circ} \mathrm{C}$.

nurses, developed fever of over $38^{\circ} \mathrm{C}$. They had nursed a patient with a severe Streptococcus pyogenes wound infection. One was admitted to an isolation cubicle, greatly distressed, where streptococcal sore throat was diagnosed. The other nurse had already seen her general practitioner; both were successfully treated with a broad-spectrum penicillin. Ten other contacts, five of whom were first line, developed fever below $38^{\circ} \mathrm{C}$. In all these cases the temperature quickly returned to normal. No restrictions on movement were imposed on those under surveillance, but names and addresses of contacts who were away from home were given to the surveillance team. Four contacts went abroad during the last five days of their surveillance. Arrangements were made for them to notify the surveillance team by telephone, telegram, or telex at the end of their surveillance period if they had remained well, and immediately if they developed fever.

Three cases of direct contact with specimens created considerable anxiety for the surveillance team. In one case a sample of the patient's blood was spilt by a medical laboratory scientific officer and then mopped up. She did not wear gloves but washed her hands afterwards and apparently had no cuts or abrasions. A second medical laboratory scientific officer, with uncovered adhesions on her hands, handled blood cultures and urine during the four days that the patient remained at St Thomas's Hospital. She spilt a specimen of urine but could not recall whether it had belonged to the infected patient. Lastly, a plumber who had several abrasions on his hands, which were unprotected, dismantled a sink in casualty into which early urine specimens had been emptied.

After a popular newspaper had made inquiries an ad-hoc meeting of staff and staff representatives at St Thomas's Hospital was held on 13 January to answer queries and allay anxiety. A conference attended by representatives of national and local radio, television, and the press was held the next day. Afterwards, as had been anticipated, the hospital telephone switchboard was inundated with queries from the public, many of whom had attended the hospital as either patients or visitors during the five days of our patient's stay. Questions were referred to the hospital information and liaison officer, who was kept informed by the district community physician.

Blood was obtained from 120 of the 124 first-line contacts and from 39 of the 49 second-line contacts to determine whether any had experienced subclinical infections. Sera were tested at the PHLS Centre for Applied Microbiology and Research, Porton Down, by immunofluorescence against Lassa fever antigen. All sera were negative at a dilution of $1 / 8$.

\section{Discussion}

A single patient with Lassa fever who spent only five days in a London teaching hospital caused a wave of disruption that spread to all parts of the hospital and created an immense amount of work for the surveillance team. Some of the 173 contacts were difficult to trace: the team made around 50 telephone calls a day up until $10 \mathrm{pm}$ during the alert. Contacts wanted to go abroad on holiday or business, and arrangements had to be made for them to stay in touch with the surveillance team.

Travel by air brings people to Britain from areas of Africa where viral haemorrhagic fevers are endemic. Mere suspicion of this diagnosis has far-reaching consequences for the patient, relatives, hospital staff, and public health services. Such a suspicion must be well founded, and accurate details of the patient's recent travels and recent contacts abroad are essential. The likelihood of exposure to Lassa fever virus is increased if there has been a journey into rural areas with substandard housing. Here the reservoir of infection, the multimammate rat (Mastomys natalensis), may enter dwellings and contaminate the environment with virus-infected secretions. Those who have recently worked in hospitals in west Africa are also in a high-risk category. In our case we could not obtain a precise history of the patient's recent movements in Nigeria, and the information that she did provide was at variance with details given later by her husband. Possibly her confusion was a manifestation of the developing illness, but communication may also have been impaired by cultural differences.

A detailed history of recent movements abroad is of paramount importance in patients such as ours with unusual and misleading clinical features. Sore throat is a common feature at onset. Our patient had no pharyngitis, but the subsequent development of cervical and facial oedema was characteristic. In spite of the persistent high fever, prostration occurred relatively late in the course of the illness. A normal peripheral blood picture or leucopenia is usual, at least during the first week of the illness, but leucocytosis has been described. ${ }^{2}$ In this case it may have been related to the extensive tissue necrosis, a superimposed bacterial infection, or impending intravascular coagulation. A relative bradycardia is expected. Initially the pulse rate may have been slow relative to the degree of fever, but the tachycardia that ensued may possibly have been the result of myocarditis.

Despite increasing awareness of the possibility of importation of viral haemorrhagic fevers, the most probable diagnosis in patients with fever arriving from the tropics will continue to be malaria, typhoid fever, or viral hepatitis. Premature implementation of public health control procedures may delay the establishment of an alternative diagnosis, which may have fatal consequences. Strict isolation and the difficulties it imposes often lead to reluctance to take vital specimens from the patient. Nevertheless, we believe that hazards may be overcome by employing a competent phlebotomist and scrupulously observing laboratory decontamination procedures. Examination of blood films for malarial parasites is essential and often must be repeated. Slides that have been fixed with $10 \%$ buffered formalin for 15 minutes may be safely examined on the open bench (Communicable Disease Surveillance Centre, unpublished information).

Previous experience suggests that there is a tendency to overreact to the risks of spread of infection within the community while insufficient emphasis is directed towards the risks within the hospital. ${ }^{3}$ Airborne transmission from person to person is probably rare and confined to patients with pulmonary disease. ${ }^{4}$ Surveillance imposes a considerable work load on public health services within the community, which is costly in terms of time, energy, and resources. The procedure is further complicated when health district boundaries have to be crossed. All this may be counterproductive and detract from more urgent measures required within the hospital.

Our experience showed how easily specimens escaped tracing within the hospital laboratory network. We failed to note, for example, that blood had been sent to the department of immunology until three days after the patient had been transferred to Coppetts Wood Hospital. By then serum had been sent from this department to the Hospital for Tropical Diseases for amoebiasis to be excluded. People who had handled the specimens were immediately notified and placed under surveillance. 
Clinical laboratory staff are exposed to a considerable hazard by having to process specimens of blood, urine, and secretions that may contain high titres of virus. Infection may occur via contamination of cuts or abrasions. Since two contacts may have been contaminated in this way it is fortunate that our patient was probably not excreting virus in the urine until after her transfer to Coppetts Wood Hospital. ${ }^{1}$ Nevertheless, it is encouraging that despite the high level of viraemia there was no evidence of clinical or subclinical infection among those who handled blood specimens.

There will always be the possibility that patients with undiagnosed Lassa fever may be admitted to district general hospitals, particularly if, as in this case, a history of residence within a rural area is not readily forthcoming. Prevention of spread within such hospitals will depend on general policies for the control of infection within the wards and safe handling of specimens within laboratories. Hospitals must have appropriate isolation facilities for managing patients with infectious diseases.

So far as we are aware, not a single case of transmission of Lassa fever from person to person has occurred outside the African continent. Hospital practice in parts of tropical Africa may be particularly hazardous because of certain factors that do not apply in other countries: patients with uncontrolled haemorrhage must often be nursed on open wards where cleanliness is inadequate and decontamination impossible, and cross- infection may occur through the necessary economy of using repeatedly unsterilised equipment such as needles.

Perhaps in view of our experiences and the comments made above some recommendations in the DHSS memorandum on Lassa fever ${ }^{5}$ should be revised.

We are grateful to Dr Brian Creamer for permission to publish details of his patient ; to many other members of staff at St Thomas's Hospital who were closely involved and associated with surveillance; and to Mrs Helen Peston (information and liaison officer) and the hospital telephonists who coped admirably with a deluge of calls.

\section{References}

${ }^{1}$ Emond RTD, Bannister B, Lloyd G, Southee TJ, Bowen ETW. A case of Lassa fever: clinical and virological findings. $\mathrm{Br} M e d f$ 1982;285:1001-2.

${ }^{2}$ Grundy DJ, Bowen ETW, Lloyd G. Isolated case of Lassa fever in Zaria, Northern Nigeria. Lancet 1980 ;ii:649-50.

${ }^{3}$ Galbraith NS, Berrie JRH, Forbes P, Young S. Public health aspects of viral haemorrhagic fevers in Britain. Roy Soc Health 7 1978;98:152-61.

4 Carey DE, Kemp GE, White HA. Lassa fever: epidemiological aspects of the 1970 epidemic. Jos, Nigeria. Trans $R$ Soc Trop Med Hyg 1972;66: 402-8.

${ }^{5}$ Department of Health and Social Security, Welsh Office. Memorandum on Lassa fever. London: HMSO, 1976.

(Accepted 2 August 1982)

\title{
European distribution of Paget's disease of bone
}

\author{
F M DETHERIDGE， P B GUYER， D J P BARKER
}

\begin{abstract}
The prevalence of Paget's disease of bone was mapped from 1416 replies to a postal questionnaire sent to radiologists throughout Western Europe. Subsequently radiological surveys were carried out in 13 towns in nine countries. The two surveys showed a remarkable geographical distribution. The prevalence of the disease was higher in Britain than in any other Western European country. Only in France did the prevalences reach the lowest values among those previously recorded in a survey of 31 British towns. The lowest rates in any country were in Sweden and Norway.
\end{abstract}

These findings have implications for the hypothesis that the disease is caused by a virus infection and suggest the existence of one or more as yet unknown cofactors.

\section{Introduction}

Clinical data suggest that Paget's disease of bone has a remarkable geographical localisation, with the highest prevalences being in Britain, Western Europe, North America, Australia, and

\footnotetext{
MRC Environmental Epidemiology Unit, Southampton General Hospital, Southampton SO9 4XY

F M DETHERIDGE, BSC, MSC, research fellow

D J P BARKER, PHD, FRCP, professor of clinical epidemiology

Department of Radiology, Southampton General Hospital, Southampton SO9 4XY

P B GUYER, DM, FRCR, consultant radiologist
}

New Zealand. ${ }^{1}$ Radiological surveys among hospital patients aged 55 and over in Britain, North America, and Australia have confirmed these high prevalences. ${ }^{2}$ In Britain the overall ageand sex-standardised prevalence in some 29000 radiographs from 31 towns was 5.0\% $(6.2 \%$ among men, $3.9 \%$ among women). ${ }^{3}$ Clinical, radiological, and necropsy data from other European countries suggest that there are pronounced variations in prevalence, but there has been no systematic study to verify this. ${ }^{2}$

We report here the results of a survey of the prevalence of Paget's disease in Western Europe based on radiologists' replies to a postal questionnaire and radiological surveys carried out in nine countries.

\section{Methods \\ POSTAL QUESTIONNAIRE SURVEY}

A postal questionnaire was sent to a notional $50 \%$ sample of radiologists in Western Europe. The sample was drawn from a listing supplied by an international mailing company which tries to maintain an up-to-date register of radiologists. The questionnaire inquired about the average frequency with which Paget's disease was seen, as either the principal abnormality or, more often, as an incidental one, and asked respondents whether they were general radiologists or specialists-for example, neuroradiologists.

In a pilot survey the questionnaire was sent to all radiologists in (a) four British towns, (b) Northern Ireland, where the prevalence was thought to be similar to that in Britain, (c) Norway, where there is evidence of a low prevalence, ${ }^{4}$ and $(d)$ Luxembourg, which is approximately in the centre of the area to be surveyed. The replies and comments received led to our modifying the question on frequency so that the number of possible responses was increased from four (once a week or more, once a month, once a year, less than once a year) to seven (once a week or more, once every two weeks, once a month, 